\title{
The effects of epidural bupivacaine on ischemia/reperfusion- -induced liver injury
}

\author{
Sarikus $Z^{1}$, Bedirli $N^{1}$, Yilmaz $G^{2}$, Bagriacik $U^{3}$, Bozkirli $F^{1}$ \\ Gazi University School of Medicine, Department of Anestesiology and Reanimation, Ankara, Turkey. \\ bozkirli@gazi.edu.tr
}

\begin{abstract}
BACKGROUND: Several animal studies showed beneficial effects of thoracic epidural anesthesia (TEA) in hippocampal, mesenteric and myocardial IR injury (2-4). In this study, we investigated the effects of epidural bupivacaine on hepatic ischemia reperfusion injury in a rat model.

MATERIAL AND METHODS: Eighteen rats were randomly divided into three groups each containing 6 animals. The rats in Group $\mathrm{C}$ had sham laparotomy. The rats in the Group S were subjected to liver IR through laparotomy and $20 \mathrm{mcg} / \mathrm{kg} / \mathrm{h} 0.9 \% \mathrm{NaCl}$ was administered to these rats via an epidural catheter. The rats in the Group B were subjected to liver IR and were given $20 \mathrm{mcg} / \mathrm{kg} / \mathrm{h}$ bupivacaine via an epidural catheter. Liver tissue was harvested for MDA analysis, apoptosis and histopathological examination after 60 minutes of ischemia followed by 360 minutes of reperfusion. Blood samples were also collected for TNF- $\alpha$, IL-1 $\beta$, AST and ALT analysis.

RESULTS: The AST and ALT levels were higher in ischemia and reperfusion group, which received only normal saline via the thoracic epidural catheter, compared to the sham group. In the ischemia reperfusion group, which received bupivacaine via the epidural catheter, IL-1 levels were significantly higher than in the other groups. TNF- $\alpha$ levels were higher in the Groups $S$ and B compared to the sham group. Bupivacaine administration induced apoptosis in all animals.

CONCLUSION: These results showed that thoracic epidural bupivacaine was not a suitable agent for preventing inflammatory response and lipid peroxidation in experimental hepatic IR injury in rats. Moreover, epidural bupivacaine triggered apoptosis in hepatocytes. Further research is needed as there are no studies in literature investigate the effects of epidural bupivacaine on hepatic ischemia reperfusion injury (Tab. 3, Fig. 3, Ref. 34). Text in PDF www.elis.sk.

KEY WORDS: thoracic epidural anesthesia, bupivacaine, ischemia reperfusion injury, liver.
\end{abstract}

\section{Introduction}

Hepatic ischemia-reperfusion (IR) injury often arises during perioperative period of an extensive hepatobiliary surgery. Toledo-Pereyra et al (5) identified hepatic IR injury as an important pathological process during an experimental liver transplantation. Two prominent mechanisms - microcirculatory distruption and intrahepatic inflammatory burst- are suspected in hepatic injury (6, 7). Ischemia and reperfusion may cause lethal hepatocyte injury or postoperative liver dysfunction. It is thought that sympathetic nerve activity has a triggering role in injury and inflammatory processes. In contrast, protective effects of sympathetic denervation in liver injury was shown $(8,9)$. There is an increasing evidence indicating both $\alpha$ - and $\beta$-adrenoreceptors damage hepatic and immune functions $(10,11)$.

${ }^{1}$ Gazi University School of Medicine, Department of Anestesiology and Reanimation, Ankara, Turkey, ${ }^{2}$ Gazi University School of Medicine, Department of Pathology, Ankara, Turkey, and ${ }^{3}$ Gazi University School of Medicine, Department of Immunology, Ankara, Turkey

Address for correspondence: F. Bozkirli, Prof, MD, Gazi University Medical Faculty, Department of Anesthesiology and Reanimation, 06510 Ankara, Turkey.

Phone: +90.312 .2024166$
Although the exact mechanism of its effects on splanchnic blood flow is not known, thoracic epidural anesthesia (TEA) may be protective against splanchnic hypo-perfusion. Recently, TEA has also been shown to ameliorate organ injury and improve outcome in sepsis, cardiovascular mortality and necrotizing pancreatitis (12-14). In the present study, it was hypothesized that TEA would increase liver blood flow due to the increase in splachnic perfusion and thus reduce the IR damage. The aim of this study was to investigate the effects of thoracic epidural bupivacaine against the IR damage in the liver via measuring the changes in AST, ALT, TNF- $\alpha$, IL- $1 \beta$ and MDA levels and investigating the histopathological changes in liver tissue.

\section{Methods}

The experimental protocol used for this study was approved by the Ethics Committee for Laboratory Animals of Gazi University and was performed in the Experimental Research Laboratory in Gazi University Hospital.

Eighteen male Wistar rats weighing 250-330 grams were used in this study. Rats were kept in separate cages, in 12 hour light and dark cycles at the room temperature of $24{ }^{\circ} \mathrm{C}$. They had free access to standard rat chow and water. 


\section{Experimental groups}

Rats were randomly divided to three groups: Group S $(n=6)$ was the sham group. Group IR ( $n=6)$ was the control group. After the induction of general anesthesia, an epidural catheter was placed and $20 \mathrm{mcg} / \mathrm{kg} / \mathrm{h}$ of $0.9 \% \mathrm{NaCl}$ was administered via this catheter. After this procedure, laparotomy was performed and IR was induced by the procedure explained below. Group IR-B (n =6) was the Bupivacaine group. After the induction of general anesthesia and the administration of $20 \mathrm{mcg} / \mathrm{kg} / \mathrm{h}$ Bupivacaine $\left(\right.$ Marcain $^{\circledR} 1 \mathrm{ml}=5 \mathrm{mg}$ Astra Zeneca, İstanbul, Türkiye) via an epidural catheter, IR was induced. General anesthesia was induced by $50 \mathrm{mg} / \mathrm{kg}$ Ketamin $\left(\operatorname{Ketalar}^{\circledR} 1 \mathrm{~mL}=50 \mathrm{mg}\right.$, Pfizer, Istanbul, Türkiye) and $2.5 \mathrm{mg} / \mathrm{kg}$ Xsylazin $(1 \mathrm{~mL}=20 \mathrm{mg}$, Egevet, Izmir, Türkiye) The rats were hydrated via a 24 Gauge catheter placed into the tail vein.

\section{Epidural catheterization}

Epidural catheterization was performed using a microsurgical technique. Briefly, each rat was placed in the prone position. The lumbar vertebral column was flexed by placing a cylinder transversely under the lower abdomen. The fourth lumbar spinal process was exposed and cut. A small hole was drilled through the cranial margin of the intervertebral space L3 to 4. Epidural catheters (A PE 10 tube with $0.61 \mathrm{~mm}$ outer diameter) were inserted at L3 to 4 and advanced to $\mathrm{T} 6$. A repeated negative aspiration test excluded subdural position of the catheter. Correct positioning of the epidural catheter was confirmed after the completion of the experiment by autopsy. All catheters were sutured to the fascia, tunneled under the skin, exteriorized at the neck, and protected by a swivel device. The epidural catheter dead-space $(28 \mathrm{~L})$ was filled with bupivacaine $0.5 \%$ or saline $0.9 \%$ according to group assignment.

\section{Induction of ischemia and reperfusion}

A midline laparotomy was performed; hepatic artery in the left portal triad was identified and clamped with a microvessel clip (Harvard Apparatus, Inc., Holliston, MA). Epidural infusions started as continuous infusion $(20 \mathrm{mcg} / \mathrm{kg} / \mathrm{h}$ of saline $0.9 \%$ and $20 \mathrm{mcg} / \mathrm{kg} / \mathrm{h}$ of bupivacaine $0.5 \%$ ) and continued until the end of the reperfusion period. During the period of ischemia, the abdominal wall incision was kept closed to prevent heat and fluid loss. The swivel device allowed continuation of the infusion during the reperfusion period and unrestricted movement of animals in the cage. After 1 hour of ischemia, the vascular clip was removed from the hepatic artery in the left portal triad to permit reperfusion, return of pulse, and the reestablishment of pink color. During the reperfusion phase, the intestines were returned to the abdominal cavity, and the laparotomy incision was closed in layers. A reperfusion period was maintained for $360 \mathrm{~min}$. After this period, 4-5 ml blood was collected via intracardiac puncture, then all rats were sacrificed and liver tissues were quickly removed.

\section{Liver function tests}

Serum levels of AST, ALT were measured with standard methods using commercial kits in Beckmann Olympus AU2700 autoanalyser.

\section{Cytokine measurement}

The blood samples were obtained and placed in microcentrifuge tubes, and the plasma was separated by centrifugation, immediately frozen, and stored at $80{ }^{\circ} \mathrm{C}$ until the time of assay. Plasma TNF- $\alpha$, and IL-1 $\beta$ levels were detected in a 96-well microtiter plate with a commercial enzyme-linked immunosorbent assay (ELISA) kit (eBioscience $\left.{ }^{\circledR}\right)$ according to the manufacturer's guidelines. All samples were tested in duplicate. The plate was read on ELX800 automated microplate readers at $450 \mathrm{~nm}$. The concentrations of TNF- $\alpha$, and IL- $1 \beta$ were calculated from a standard curve and expressed in picogram per milliliter $(\mathrm{pg} / \mathrm{mL})$. The lower limit of detection for ELISA was 8 to $16 \mathrm{pg} / \mathrm{mL}$.

\section{Processing and preparation of tissue}

The tissue specimens were rapidly excised, washed in icecold normal saline, blotted, frozen in liquid nitrogen, and stored at $-80{ }^{\circ} \mathrm{C}$ until use. $10 \%(\mathrm{w} / \mathrm{v})$ homogenation of liver tissues were made in Tris- $\mathrm{HCl}(0.1 \mathrm{M}, \mathrm{pH}$ 7.4) using an ice-chilled glass homogenizing vessel in a homogenizer fitted at $15000 \mathrm{rpm}$. The suspended mixture was centrifuged at $1000 \mathrm{~g}$ for $10 \mathrm{~min}$ at $4{ }^{\circ} \mathrm{C}$ in a refrigerated centrifuge.

\section{Liver MDA activity assay}

The extent of lipid peroxidation was determined as the concentration of thiobarbituric acid reactive substances (TBARS), according to the method of Ohkawa et al (15). Briefly, $100 \mu \mathrm{L}$ of liver homogenates or MDA standards were pipetted into test tubes containing $1.5 \mathrm{~mL}$ of $20 \%(\mathrm{w} / \mathrm{v})$ glacial acetic acid ( $\mathrm{pH} 3.5), 200$ $\mu \mathrm{L}$ of $8.1 \%(\mathrm{w} / \mathrm{v})$ sodium dodecyl sulphate (SDS), $1.5 \mathrm{~mL}$ of $0.8 \%$ (w/v) thiobarbituric acid (TBA) and $250 \mu \mathrm{L}$ of distilled water. The test tubes were incubated at $95^{\circ} \mathrm{C}$ for 60 minutes with a marble on top of each test tube. After incubation, the test tubes were cooled and then centrifuged at $4000 \times \mathrm{g}$ for 10 minutes. The amount of malondialdehyde (MDA) formed was measured spectrophotometrically at $532 \mathrm{~nm}$. 1,1,3,3-Tetraethoxypropane (TEP), a form of MDA, was used as standard in this assay. TBARS concentration was expressed as nmol of MDA per mg protein.

\section{Histological determinations}

All of the specimens were fixed in $10 \%$ buffered neutral formalin and embedded in paraffin. To visualize myocardial lesions at different levels, the entire heart was cut into four segments from apex to bottom. The segments were embedded in paraffin and $4-\mu \mathrm{m}$ thickness cross-sections were cut from each segment.

The slides were stained with Hematoxylin-Eosin (Bio-optica, Milano, Italy) for the evaluation of the tissues' histological features. The slides were evaluated under a light microscope for apoptosis, inflammatory activity and IR injury.

\section{Statistical analysis}

Statistical analysis was performed by using the SPSS 17.0 packet program. Continuous variables were expressed as the mean $\pm \mathrm{SD}$. Values of $\mathrm{p}<0.05$ were accepted as significant. In order to identify normal or abnormal distributions, Shapiro-Wilk test was used. One way ANOVA was used in normally distributed indepen- 
Tab. 1. AST, ALT, IL-1 $\beta$ ve TNF- $\alpha$ levels in study groups (mean \pm SS).

\begin{tabular}{|c|c|c|c|c|}
\hline & $\begin{array}{c}\text { Group C } \\
(\mathrm{n}=6)\end{array}$ & $\begin{array}{c}\text { Group S } \\
(\mathrm{n}=6)\end{array}$ & $\begin{array}{c}\text { Group B } \\
(\mathrm{n}=6)\end{array}$ & $\mathrm{p}^{* *}$ \\
\hline$\overline{\mathrm{AST}}(\mathrm{U} / \mathrm{L})$ & $\begin{array}{c}242.67 \pm 93.14 \\
(155-393) \\
\end{array}$ & $\begin{array}{c}1981.50 \pm 964.33^{*} \\
(523-3176)\end{array}$ & $\begin{array}{c}1344.17 \pm 1075.70 \\
(496-3344) \\
\end{array}$ & 0.009 \\
\hline$\overline{\mathrm{ALT}(\mathrm{U} / \mathrm{L})}$ & $\begin{array}{c}82.83 \pm 20.20 \\
(62-120)\end{array}$ & $\begin{array}{c}2268.00 \pm 945.64 * \\
(704-3400)\end{array}$ & $\begin{array}{c}1780.67 \pm 1887.17 \\
(526-5322)\end{array}$ & 0.018 \\
\hline $\mathrm{IL}-1$ beta $(\mathrm{pg} / \mathrm{mL})$ & $\begin{array}{c}8.07 \pm 4.54 \\
(2.83-13.32)\end{array}$ & $\begin{array}{l}24.84 \pm 14.88 \\
(3.78-43.10)\end{array}$ & $\begin{array}{c}58.96 \pm 16.58^{*} . \& \\
(36.35-76.13)\end{array}$ & $<0.0001$ \\
\hline TNF alfa $(\mathrm{pg} / \mathrm{mL})$ & $\begin{array}{c}12.54 \pm 4.18 \\
(9.07-18.21)\end{array}$ & $\begin{array}{l}33.31 \pm 14.35^{*} \\
(17.37-59.49)\end{array}$ & $\begin{array}{l}50.91 \pm 17.04 * \\
(28.23-70.60)\end{array}$ & 0.001 \\
\hline
\end{tabular}

$\mathrm{p}^{* *} \mathrm{p}<0.05$ with ANOVA, $* \mathrm{p}<0.05$ : Compared to Group $\mathrm{C}, \& \mathrm{p}<0.05$ : Compared to Group S

Tab. 2. Tissue MDA levels in rat hepatic tissue specimens (mean $\pm \mathrm{SS})$.

\begin{tabular}{lcccc}
\hline & $\begin{array}{c}\text { Group C } \\
(\mathrm{n}=6)\end{array}$ & $\begin{array}{c}\text { Group S } \\
(\mathrm{n}=6)\end{array}$ & $\begin{array}{c}\text { Group B } \\
(\mathrm{n}=6)\end{array}$ & $\mathrm{p}^{* *}$ \\
\hline MDA & $120.63 \pm 4.80$ & $126.10 \pm 9.30$ & $127.87 \pm 6.43$ & \\
& $(116.20-127.40)$ & $(114-141.40)$ & $(119-137.20)$ & 0.216 \\
\hline
\end{tabular}

$\mathrm{p}^{* *} \mathrm{p}<0.05$ with ANOVA, ${ }^{*} \mathrm{p}<0.05$ : Compared to Group C, \& $\mathrm{p}<0.05$ : Compared to Group S

Tab. 3. Histopathological data of rat hepatic tissue (n \%).

\begin{tabular}{lcccc}
\hline & $\begin{array}{c}\text { Group C } \\
(\mathrm{n}=6)\end{array}$ & $\begin{array}{c}\text { Group S } \\
(\mathrm{n}=6)\end{array}$ & $\begin{array}{c}\text { Group B } \\
(\mathrm{n}=6)\end{array}$ & $\mathrm{p}^{* *}$ \\
\hline Inflammatory activity (exist/absent) & $0 / 6$ & $0 / 6$ & $0 / 6$ & - \\
\hline Apoptosis (exist/absent) & $6(100) / 0$ & $5(83.3) / 1(16.7)$ & $0 / 6(100) * \&$ & $<0.0001$ \\
\hline IR injury (exist/absent) & $6(100) / 0$ & $5(83.3) / 1(16.7)$ & $3(50) / 3(50)$ & +0.069 \\
\hline $\mathrm{p}^{* *} \mathrm{p}<0.05$ with Chi Square test, $* \mathrm{p}<0.05:$ Compared to Group C, \& $\mathrm{p}<0.05:$ Compared to Group $\mathrm{S}$ & &
\end{tabular}

dent data. Significant differences between parameters in the same group were analyzed with Bonferroni test. Chi-square or Fisher Exact Chi-square tests were used for evaluating inflammatory activity, apoptosis and ischemia-reperfusion damage.

\section{Results}

\section{Biochemical findings}

We found significant differences between groups in terms of AST enzyme levels $(p=0.009)$. AST levels were significantly higher in the Group S than Group C $(p=0.001)$ (Tab. 1). Also, significant differences were found between groups in terms of ALT enzyme levels $(p=0.018)$. ALT levels were higher in the Group $S$ than the Group C $(p=0.022)$ (Tab. 1). There were significant dif- ferences between the groups in terms of IL-1 $\beta$ levels $(p<0.0001)$. IL- $1 \beta$ levels in the Group S and B were significantly higher than in the Group C ( $p=0.045, p<0.0001$, respectively) (Tab. 1).

We found significant inter-group differences in TNF- $\alpha$ levels $(p=0.001)$. TNF- $\alpha$ levels were significantly higher in the Group $\mathrm{B}$ than in the Group C and S ( $\mathrm{p}=0.001 . \mathrm{p}<0.0001$, respectively) (Tab. 1).

We couldn't find any significant differences between study groups in terms of tissue MDA levels $(p=0.216)$ (Tab. 2).

\section{Histopathological findings}

We found normal hepatic tissue microanatomical characteristics in histological evaluation of specimens belonged to all study animals. In the group S, only in a single animal we found cellu-

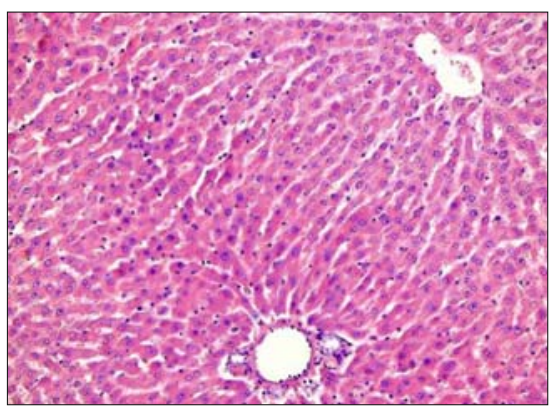

Fig. 1. Normal liver parenchyma.

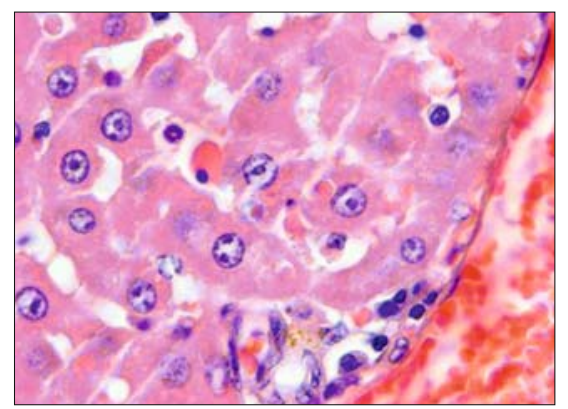

Fig. 2. Apoptotic bodies.

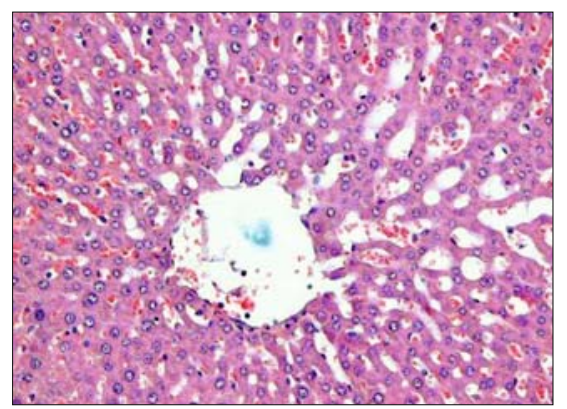

Fig. 3. Irregular sinusoidal dilatations around central vein. 
lar damage findings including a congestion around portal fields, nuclear loss of hepatocytes, appearance of collapsed and irregular hepatocyte lines. In the group B, cellular damage findings were found in 3 animals. Additionally, in this group we found apoptotic objects in forms of cell groups or necrotic single cells. Irregular sinusoidal dilatations were partly identified around the central veins. Also mitotic figures - refer to regenerative hepatocyte activity- were identified. Histopathological findings are represented in Table 3. Also, microscopical appearances of specimens are showed in Figures 1, 2 and 3.

\section{Discussion}

In this study, we hypothesized that epidurally infused bupivacaine $(0.5 \%)$ would protect hepatic tissue against ischemia reperfusion injury via increasing splanchnic and hepatic perfusion that was proven in previous experimental model (16). However, our findings have suggested that epidural bupivacaine -in contrast to our hypothesis- resulted in an increased systemic inflammatory response, lipid peroxidation in liver tissue and apoptosis of hepatocytes.

An increased sympathetic nerve activity is one of the leading factor in hepatic injury and immune response. Triggered intrahepatic inflammation and liver injury secondary to increased sympathetic system activation were shown in different experimental studies, while decreased sympathetic activation was defined as a preventing factor in hepatic injury (9-11).

Thoracic epidural anesthesia (TEA) blocks sympathetic tone, denervates afferent sensorial nerves and results in regional anesthesia and analgesia. There is an increasing evidence that shows beneficial effects of TEA in various experimental in vitro, in vivo studies conducted for clinical entities include sepsis, IR injury, cardiovascular mortality, necrotizing pancreatitis, inflammatory processes $(12-14,17)$. However, in contrast to supporting data there are several reports that showed no beneficial effects of TEA in experimental models of inflammation and IR (18-21).

Wei et al (18) designed an in vitro experiment with activated human umblical vein endothelial cells (HUVEC) in order to investigate different doses of lidocaine effect on inflammation. The authors reported that high dose lidocaine $(0,5 \mathrm{mg} / \mathrm{mL})$ reduced the IL-1 $\beta$, IL-6 and IL-8 concentrations while low dose $(0.005 \mathrm{mg} /$ $\mathrm{ml})$ lidocaine couldn't make any effective decrement in plasma concentrations of ICAM-1, IL-1 $\beta$,IL-6 and IL-8. Similarly, we found that epidural bupivacaine at clinical doses couldn't exert any anti-inflammatory effect that presented with increased plasma IL-1 $\beta$ levels.

Huang et al (20) investigated anti-inflammatory effects of bupivacaine on murine macrophages that incubated with lipopolysaccaride (LPS) alone (100 ng/ml) or LPS plus bupivacaine (1, 10 or 100 mikroM). They reported that bupivacaine significantly inhibited the COX-2 transcription and PGE (2) production in a dosedependent manner. Also, they showed that bupivacaine inhibited TNF-alpha, IL-1beta, and IL-6 production triggered by LPS in a dose dependent manner. Another interesting finding of this study was not achieved a significant bupivacaine effect on endotoxin induced IL-10 production. In contrast to these findings, we found that epidurally administered bupivacaine caused an increased TNF- $\alpha$ and IL- $1 \beta$ levels in hepatic IR rat model.

In another in vitro study Kiefer et al (21) designed the Staphylococcus aureus added inflammation model; and they showed a reduced reactive oxygen species generation, $\mathrm{CD} 11 \mathrm{~b}$ expression and decreased granulocyte phagocytosis activity with lidocaine and bupivacaine treatments only at the highest concentrations (1846 $\mu \mathrm{M}$ and $770 \mu \mathrm{M}$ respectively). According to these results of different investigations, we can state that different local anesthetic agents exert different anti-inflammatory effects in a dose dependent manner and these anti-inflammatory effects may be achieved only with the highest in vitro doses of agents.

Lipid peroxidation secondary to reactive oxygen species is one of the major factors that leads IR injury. Malondialdehyde is an end-product in lipid peroxidation (22). In our study, we couldn't show any differences between the study groups in terms of tissue MDA levels. In contrast to our findings, Bedirli et al (23) showed strong anti-inflammatory effects of $20 \mathrm{mcL} / \mathrm{h}$ epidurally administered bupivacaine at $0.5 \%$ concentration in a mesenteric IR rat model. They showed that bupivacaine reduced plasma TNF- $\alpha$, IL-6, IL-1 $\beta$ and tissue MDA levels significantly. Also, inflammation related apoptosis was significantly decreased with bupivacaine treatment.

Several studies showed a strong correlation between bupivacaine and cellular apoptosis via inhibition of complex I in mitochondria, impairing oxidative phosphorylation which resulted in a reduced ATP production and disrupting mitochondrial membrane potential $(24,25)$. Although the exact mechanism is not known, it ss thought that local anesthetic induced apoptosis was related to mitogen activated protein kinase pathway $(26,27)$. Boselli et al (28) and Castro et al (29) showed a significant relationship between local anesthetic related neurotoxicity and cellular apoptosis. Similarly, Park et al (30) reported that bupivacaine induced schwann cell apoptosis, while in another study, Lu et al (31) showed a correlation between bupivacaine treatment and mitochondrial apoptosis. In our study, we found a significant hepatocyte apoptosis in bupivacaine group correlated to previous studies conducted by Park et al and Lu et al $(30,31)$.

Lee et al (32) investigated the effects of various local anesthetics (lidocaine $5 \%$, bupivacaine $1-0.5 \%$ and tetracaine $2.5 \%$ ) on systemic inflammation and renal functions in a renal IR injury model. They concluded that continuous infusion of bupivacaine $1 \%$ resulted in an impaired renal functions at 24 th and 48 th hours of IR. Additionally, in all local anesthetic groups, the apoptosis rates (lidocaine, bupivacaine and tetracaine respectively), mRNA -coding ICAM-1 and TNF alfa- expression were significantly higher than in the control group. In the bupivacaine $0.5 \%$ group, renal functions were protected in contrast to other study groups. Another interesting finding of this study was an unchanged IL$1 \beta$ expression rate in all study groups. In our study, we couldn't find any differences for IL-1 $\beta$ levels between the bupivacaine and control groups. However, apoptosis rates were significantly higher in the bupivacaine $0.5 \%$ group than rates noted in sham and control groups. 
Freise et al (33) investigated the effects of bupivacaine $0.5 \%$ ( $15 \mathrm{mcl} / \mathrm{h}$ continuous infusion via thoracic epidural route) on rat caecal ligation and perforation induced sepsis model. The results of this study indicated that TEA treatment with bupivacaine 0.5 $\%$ was ineffective in the restoring sepsis induced sinusoidal vasoconstriction, sinusoidal leukocytes adhesion, increased TNF- $\alpha$ levels and increased serum ALT, AST levels. Another study conducted by Freise et al (34) showed ameliorated apoptosis rates in experimentally induced pancreatitis treated with continuous infusion of thoracic epidural bupivacaine $(0.5 \%$ concentration, $15 \mathrm{mcl} / \mathrm{h}$ infusion rate) in rats. In addition, they showed an ameliorated sinusoidal vasoconstriction with bupivacaine treatment. In contrast to this study, we showed high apoptosis rates in all bupivacaine treated $(0.5 \%$ concentration, $20 \mathrm{mcg} / \mathrm{kg} / \mathrm{h}$ infusion rate) rats.

In summary, there are conflicting results regarding the thoracic epidural bupivacaine treatment in experimental IR injury and sepsis models designed for various organ systems. According to these data, we can state that one explanation of these different results may be the different experimental designs -drug concentration, IR injury modal, time interval between IR and scarification etc- of investigations. Additionally we believe that the obtained results may vary depend on the liver is primarily or secondarily affected organ. Future studies need to be conducted in order to clearly determine thoracic epidural bupivacaine effects on hepatic IR injury.

\section{References}

1. Teoh NC, Farrell GC. Hepatic ischemia-reperfusion injury: pathogenic mechanisms and basis for hepatoprotection. J Gastronenterol Hepatol 2003; 18: 891-902.

2. Groban L, Zvara DA, Deal DD, Vernon JC, Carpenter RL. Thoracic epidural anesthesia reduces infarct size in a canine model of myocardial ischemia and reperfusion injury. J Cardiothorac Vasc Anesth 1999; 13 (5): 579-585.

3. Bedirli N, Akyürek N, Kurtipek O, Kavutcu M, Kartal S, Bayrak$\operatorname{tar} \mathrm{AC}$. Thoracic epidural bupivacaine attenuates inflammatory response, intestinal lipid peroxidation, oxidative injury, and mucosal apoptosis induced by mesenteric ischemia/reperfusion. Anesth Analg 2011; 113 (5): 1226-1232.

4. Li X, Huo X, Zhang C, Ma X, Han F, Wang G. Role of continuous high thoracic epidural anesthesia in hippocampal apoptosis after global cerebral ischemia in rats. Cell Physiol Biochem 2014; 34 (4): $1227-1240$.

5. Toledo-Pereyra LH, Simmons RL, Najarian JS. Protection of the ischemic liver by donor pretreatment before transplantation. Am J Surg 1975; 129: 513-517.

6. Gregory SH, Wing EJ. Neutrophil-Kupffer cell interaction: a critical component of host defenses to systemic bacterial infections. J Leukoc Biol 2002; 72: 239-248.

7. Pannen BH. New insights into the regulation of hepatic blood flow after ischemia and reperfusion. Anesth Analg 2002; 94: 1448-1457.

8. Schemmer P, Schoonhoven R, Swenberg JA, Bunzendahl H, Thurman RG. Gentle in situ liver manipulation during organ harvest decreases survival after rat liver transplantation: role of Kupffer cells. Transplantation 1998, 65: 1015-1020.

9. Schemmer P, Bunzendahl H, Raleigh JA, Thurman RG. Graft survival is improved by hepatic denervation before organ harvesting. Transplantation 1999; 67: 1301-1307.

10. Zhou M, Das P, Simms HH, Wang P. Gut-derived norepinephrine plays an important role in up-regulating IL-1beta and IL-10. Biochim Biophys Acta 2005; 1740: 446-452.

11. Yang S, Zhou M, Chaudry IH, Wang P. Norepinephrine-induced hepatocellular dysfunction in early sepsis is mediated by activation of alpha2-adrenoceptors. Am J Physiol Gastrointest Liver Physiol 2001; 281: G101-102.

12. Freise H, Lauer S, Anthonsen S, Hlouschek V, Minin E, Fischer LG et al. Thoracic epidural analgesia augments ileal mucosal capillary perfusion and improves survival in severe acute pancreatitis in rats. Anesthesiology 2006; 105: 354-359.

13. Daudel F, Freise H, Westphal M, Stubbe HD, Lauer S, Bone HG et al. Continuous thoracic epidural anesthesia improves gut mucosal microcirculation in rats with sepsis. Shock 2007, 28: 610-614.

14. Nygård E1, Kofoed KF, Freiberg J, Holm S, Aldershvile J, Eliasen $\mathbf{K}$ et al. Effects of high thoracic epidural analgesia on myocardial blood flow in patients with ischemic heart disease. Circulation 2005; 111 (17): 2165-2170.

15. Ohkawa H, Ohishi N, Yagi K. Assay for lipid peroxides in animal tissues by thiobarbituric acid reaction. Anal Biochem 1979; 95: 351-358.

16. Mutz C,Vagts DA Thoracic Epidural Anaesthesia in sepsis -is it harmful or ptotective Crit Care 2009; 13 (5): 182.

17. Rank N, Michel C, Haertel C, Lenhart A, Welte M, Meier-Hellmann A et al. $\mathrm{N}$-acetylcysteine increases liver blood flow and improves liver function in septic shock patients: results of a prospective, randomized, double-blind study. Crit Care Med 2000; 28: 3799-3807.

18. Wei Lan, Harmon DC, Wang JH, Shorten GD, Redmond PH. Activated Endothelial Interleukin-1, -6 , and -8 Concentrations and Intercellular Adhesion Molecule-1Expression Are Attenuated by Lidocaine. Anesth Analg 2005; 100 (2): 409-412.

19. Kawasaki C, Kawasaki T, Ogata M, Sata T, Chaudry IR. Lidocaine EnhancesApoptosis and Suppresses MitochondrialFunctions of Human Neutrophil In Vitro. J Trauma 2010; 68: 401-408.

20. Huang YH, Tsai PS, Huang CJ. Bupivacaine inhibits COX-2 expression, PGE2, and cytokine production in endotoxin-activated macrophages. Acta Anaesthesiol Scand 2008; 52: 530-535.

21. Kiefer RT, Ploppa A, Krueger WA, Plank M, Nohé B. Local Anesthetics Impair Human Granulocyte Phagocytosis Activity, Oxidative Burst, and CD11b Expression in Response to Staphylococcus aureus. Anesthesiology 2003; 98: 842-848.

22. Requena JR, Fu MX, Ahmed MU, Jenkins AJ, Lyons TJ, Thorpe SR. Lipoxidation products as biomarkers of oxidative damage to proteins during lipid peroxidation reactions. Nephrol Dial Transplant 1996; 5: $48-53$.

23. Bedirli N, Akyürek N, Kurtipek O, Kavutcu M, Kartal S, Bayraktar AC. Thoracic Epidural Bupivacaine Attenuates Inflammatory Response, Intestinal Lipid Peroxidation, Oxidative Injury, and Mucosal Apoptosis Induced by Mesenteric Ischemia/Reperfusion. Anesth Analg 2011;113: 1226-1232. 


$$
\text { 41-46 }
$$

24. Kim HJ, Sung SR, Seo KS, Lim SW, Yoon TG. Bupivacaine induced apoptosisin the primary cultured cardiomyocytes via p38MAPKs. Korean J Anesthesiol 2006; 50: S48-S56.

25. Lee JC, Kassis S, Kumar S, Badger A, Adams JL. p38 mitogen activated protein kinase inhibitors-mechanisms therapeutic potentitial. Pharmacol Ther 1999; 82: 389-397.

26. Gold MS, Reichling DB, Hampl KF, Drasner K, Levine JD. Lidocaine toxicity in primary afferent neurons from the rat. J Pharmacol Exp Ther 1998; 285: 413-421.

27. Grethe S, Ares MP, Andersson T, Porn-Ares MI. p38 MAPK mediates TNF-induced apoptosis in endothelialcells via phosphorylation and down regulation of bcl-x(L). Exp Cell Res 2004; 298: 632-642.

28. Boselli E, Duflo F, Debon R, Allaouchiche B, Chassard D, Thomas L, Portoukalian J. The induction of apoptosis by local anesthetics: a comparison between lidocaine and ropivacaine. Anesth Analg 2003; 96 (3): 755-756.

29. Perez-Castro R, Patel S, Garavito-Aguilar ZV, Rosenberg A, Recio-Pinto $\mathbf{E}$, Zhang $\mathbf{J}$ et al. Cytotoxicity of local anesthetics in human neuronal cells. Anaesth Analg 2009; 108 (3): 997-1007.
30. Park CJ, Park SA, Yoon TG, Lee SJ, Yum KW, Kim HJ. Bupivacaine induces apoptosis via ROS in the Schwann cell line. J Dent Res 2005; 84 (9): 852-857.

31. Lu J, Xu SY, Zhang QG, Xu R, Lei HY. Bupivacaine induces apoptosis via mitochondria and p38 MAPK dependent pathways. Eur J Pharmacol 2011; 657: 51-58.

32. Lee HT, Krichevsky IE, Xu H, Ota-Setlik A, D'Agati VD, Emala CW. Local anesthetics worsen renal function after ischemia-reperfusion injury in rats. Am J Physiol Renal Physiol 2004; 286: 111-119.

33. Freise H, Daudel F, Grosserichter C, Lauer S, Hinkelmann J, Van Aken HK. Thoracic epidural anesthesia reverses sepsis-induced hepatic hyperperfusion andreduces leukocyte adhesion in septic rats. Crit Care 2009; 13: R116.

34. Freise H, Lauer S, Konietzny E, Hinkelmann J, Van Aken HK, Lerch MM. Hepatic effects of thoracic epidural analgesia in experimental severe acute pancreatitis. Anesthesiology 2009; 111: 1249-1256.

Received April 14, 2015. Accepted September 20, 2015. 